\title{
Potential Applications of Conducting Polymers to Reduce Secondary Bacterial Infections among COVID-19 Patients: a Review
}

\author{
Mohd Muzamir Mahat ${ }^{1}$ (D) Awis Sukarni Mohmad Sabere ${ }^{2} \cdot$ Juzaili Azizi $^{3} \cdot$ Nur Asyura Nor Amdan $^{4}$
}

Received: 4 January 2021 / Accepted: 9 February 2021 / Published online: 24 February 2021

(C) Qatar University and Springer Nature Switzerland AG 2021

\begin{abstract}
The COVID-19 pandemic is a motivation for material scientists to search for functional materials with valuable properties to alleviate the risks associated with the coronavirus. The formulation of functional materials requires synergistic understanding on the properties of materials and mechanisms of virus transmission and disease progression, including secondary bacterial infections that are prevalent in COVID-19 patients. A viable candidate in the struggle against the pandemic is antimicrobial polymer, due to their favorable properties of flexibility, lightweight, and ease of synthesis. Polymers are the base material for personal protective equipment (PPE), such as gloves, face mask, face shield, and coverall suit for frontliners. Conducting polymers (CPs) are polymers with electrical properties due to the addition of dopant in the polymer structure. The conductivity of polymers augments their antiviral and antibacterial properties. This review discusses the types of CPs and how their properties could be exploited to ward off bacterial infections in hospital settings, specifically in cases involving COVID-19 patients. This review also covers common CPs fabrication techniques. The key components to produce CPs at several possibilities to fit the current needs in fighting secondary bacterial infections are also discussed.
\end{abstract}

Keywords Conducting polymers $\cdot$ Personal protective equipment (PPE) $\cdot$ COVID-19 $\cdot$ Secondary bacterial infections

Mohd Muzamir Mahat

mmuzamir@uitm.edu.my

Awis Sukarni Mohmad Sabere

awissabere@iium.edu.my

Juzaili Azizi

juzaili.azizi@usm.my

Nur Asyura Nor Amdan

asyura@moh.gov.my

1 Textile Research Group, Faculty of Applied Sciences, Universiti Teknologi MARA, 40450 Shah Alam, Selangor, Malaysia

2 Kulliyyah of Pharmacy, International Islamic University Malaysia, Bandar Indera Mahkota, 25200 Kuantan, Pahang, Malaysia

3 Centre for Drug Research, Universiti Sains Malaysia, 11800 Penang, Malaysia

4 Bacteriology Unit, Infectious Disease Research Centre, Institute for Medical Research, National Institutes of Health, Setia Alam, 40170 Shah Alam, Selangor, Malaysia

\section{Introduction}

The electrical conductivity of conducting polymers (CPs) is the major factor behind its versatile applications. These properties are unique as they can be tuned according to specific needs and environments. For example, CPs with the conductivity of $10 \mathrm{~S} / \mathrm{cm}$ can normally be found in cardiac applications [1-5]. CPs with the conductivity of $2 \mathrm{~S} / \mathrm{cm}$ can aid in resistance against bacterial resistance when embedded within a fabric [6-12]. Several factors determine the conductivity of CPs, including their classification, types of dopant, substrate, processing techniques, and the nature of the polymer form.

Conducting polymers are synthesized with chemical polymerization. In this method, a dopant is incorporated in the polymer structure to impart conductivity to the polymer. Other methods to induce conductivity are electrochemical method [13-16] and redox method [17-21]. The inclusion of CPs in fabrics is the precedence for bioelectronics application [22-31]. Several techniques can be employed to achieve conductivity properties that are in par with the intended functionalities. One of the most crucial techniques is the doping process [32-38] where the inclusion of dopants within the polymer can be optimized according to the desired properties. 


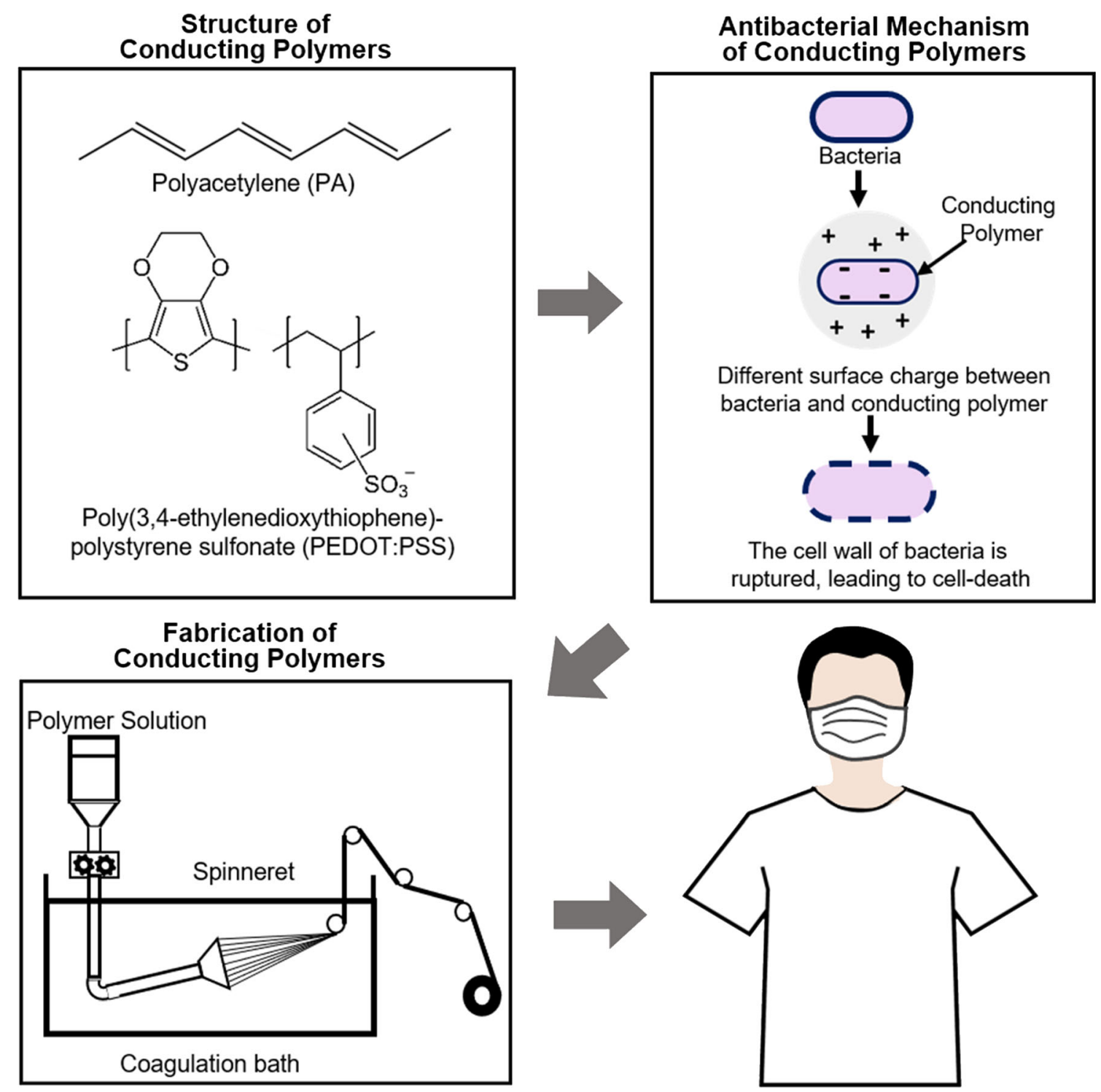

Fig. 1 Illustration on the mechanistic potential of CPs utilization for reducing potential bacterial infections among COVID-19 patients

A key element to comprehend the bigger picture of bacterial infections among COVID-19 patients is the understanding of the relationship between bacterial growth and the application of polymers with the right properties. Figure 1 illustrates the mechanistic potential of CPs in minimizing bacterial infections among COVID-19 patients.

In this review, the utilization of CPs as a potential candidate to repel secondary bacterial infection among COVID-19 patients will be discussed. The types of CPs and the unique challenges in fabricating these functional materials are presented. CPs can be integrated into PPE by embedding it into the fiber or coating the surface of PPE with CPs. The potential mechanisms of antibacterial activities in CPs are explained. The tuning of the materials' properties, especially in reducing bacterial transmission, is proposed for deeper examination in future research. This review provides valuable insights of $\mathrm{CPs}$ manipulations in addressing secondary bacterial infections among COVID-19 patients. It is hoped that the synergy between materials scientist and microbiologist can pave the way for advanced functional materials that will change the way we look at infection preventive measure.

\section{Conducting polymers (CPs)}

Even though polymers are known for being lightweight, easy to be processed, durable, and low cost, they carry the disadvantage of being electrically insulating. However, the molecular structure can be modified to produce polymers that can conduct electricity. The end result is known as conducting polymers (CPs). This type of polymer fuses the desired characteristics of plastics and metal, since CPs can be electrically conductive 
while maintaining the flexibility of plastics [39]. Generally, these electrically conducting polymers are converted via oxidation or reduction reaction. CPs comprise $\pi$-conjugated polymers that are delocalized along the backbone [40]. Therefore, electrons can easily shift along the backbone of the polymer to produce electrical current as illustrated in Fig. 2. CPs' conjugation length, degree of crystallinity, and interactions are the parameters that influence the physical properties of CPs [40].

Over the past few decades, CPs such as polyacetylene (PA), polyaniline (PANI), polypyrrole (PPy), poly (p-phenylenevinylene) (PPV), and poly (3,4-ethylene dioxythiophene) (PEDOT) have commanded attention in the theoretical and experimental spheres. Being inexpensive, easy to be synthesized with high flexibility contributes to the popularity of CPs among researchers [41-44]. Examples of CPs are shown in Fig. 3.

The conductivity value of CPs can be increased by doping [46]. Doping is the process of introducing another element or electron to the system and allowing the electrical charge to move seamlessly on the polymer backbone. The transport of electrons is driven by the movement of delocalized electrons through a conjugated system or intrinsically conducting polymer [47]. This theory is supported by the evidence from the study of Gochnauer and Gilani [48] where they proved that a system with conjugated or delocalized double bond can transport charges or electrons effectively.

By removing (oxidation) or inserting (reduction) electrons into the structure, the properties of the system can be manipulated, such as its color, porosity, and volume [39]. In the sequence of $\mathrm{p}$-bonds, the p-orbitals overlap each other. This overlap makes it possible for the electrons to pass freely between the atoms [13] and thus empowering its electrical conductivity.

According to Fan et al. [46], the electrical conductivity of undoped CPs is similar to those of other insulating polymers $\left(10^{-12} \mathrm{~S} / \mathrm{cm}\right)$. However, with doping, CPs' electrical conductivity can be increased up to $10^{2} \mathrm{~S} / \mathrm{cm}$, as shown in Fig. 4.

Fan and Ouyang [44] reported that the electrical conductivity of poly (3, 4-ethylene dioxythiophene): poly (styrenesulfonate) (PEDOT: PSS) can be improved by doping with organic solvent, ionic liquid, and intense acid treatment.
However, some ionic liquids (ILs) and strong acid treatment are rarely used because of their higher toxicity and may exhibit higher viscosity since these characteristics can impede the mobility of ion. This repercussion does not bode well in applications that require instant reaction [49]. In 2019, Lingstedt et al. suggested the application of dimethyl sulfoxided (DMSO), which is a non-toxic organosulfur compound. DMSO is a safer alternative for secondary dopant in biomedical application [50].

Lee et al. [51] discovered that the doping of PEDOT: PSS with DMSO induced morphological changes. The observed changes were an increase in PEDOT grain size and improved connectivity between PEDOT chains. These changes contributed to heightened electrical conductivity of PEDOT: PSS. Chen et al. [52] reported that DMSO aligned the PEDOT grains which improved the electrical flow between PEDOT grains and increased the conductivity of up to $1100 \mathrm{~S} / \mathrm{cm}$. Lucius et al. [53] reported that the cohesion between PEDOT molecules could be one of the factors that improves the electrical conductivity of PEDOT: PSS. The addition of DMSO may breaking the bonds between the inter part of PSS and the cohesion of PEDOT grains.

On the morphological aspect, pure PEDOT: PSS has weaker inter-PSS hydrogen bonding, which impedes the charge transfer mobility. According to Gueye et al. [54], morphological changes, such as increasing the grain size of PEDOT and promoting connection between PEDOT chains, can be induced with DMSO doping. The conductivity of PEDOT: PSS increased proportionally to the size PEDOT grains.

\section{COVID-19 and bacterial infections}

COVID-19 is an influenza-like disease that first emerged in December 2019 in Wuhan, China. It is caused by the severe acute respiratory syndrome coronavirus 2 (SARS-CoV-2). COVID-19 caught the attention of the World Health Organization (WHO) due to its widespread infectivity. COVID-19 was declared as a pandemic on 11 March 2020

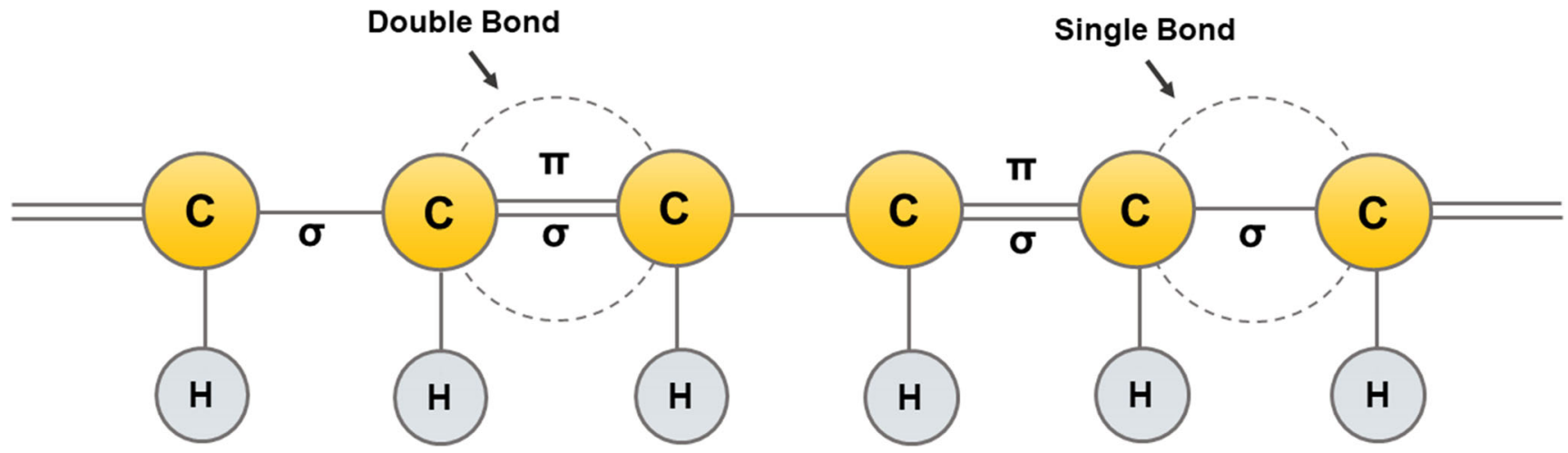

Fig. 2 Simplified schematic of a conjugated backbone: a chain containing alternating single and double bonds inspired by [13]

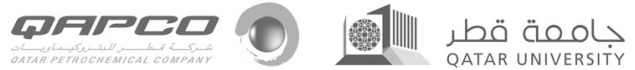




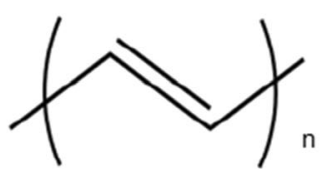

Polyacetylene (PA)<smiles>CC(C)(C)c1ccc(C(C)(C)C)s1</smiles>

Polythiophene (PT)<smiles>CC(C)(C)c1ccc(C(C)(C)C)[nH]1</smiles>

Polypyrrole (PPy)

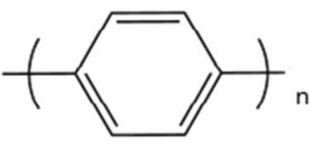

Polyparaphenyl (PPP)<smiles>CC(C)(C)c1sc(C(C)(C)C)c2c1OCCO2</smiles>

Poly(3,4-ethylenedioxythiophene) (PEDOT)

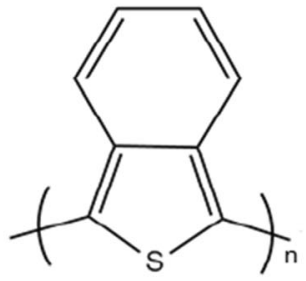

Polyisothianaphthene (PITN)<smiles>[R]c1cc(C(C)(C)C)sc1C(C)(C)C</smiles>

Poly(3-alkylthiophene) (P3AT)<smiles>CC=Cc1cccc(C(C)(C)C)c1</smiles>

Polyparaphenyl vinylene (PPV)

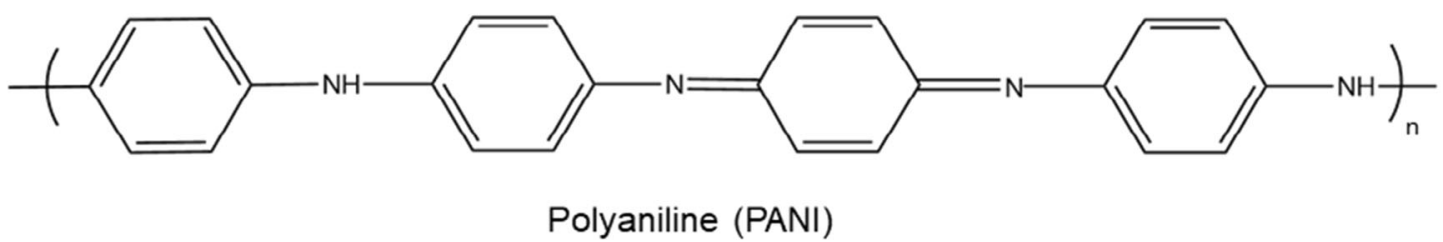

Fig. 3 Chemical structure of conducting polymers [45]

when daily cases of infection in most countries shot to an alltime high in 2020 [55]. By 28 December 2020, over $79,673,754$ cases have been recorded with $1,761,38$ fatalities in 216 countries [56]. Like other viruses of the genus Betacoronavirus, SARS-CoV-2 is a spherical coronavirus with spike-like glycoproteins on the viral envelope surface [57]. SARS-CoV-2 is an airborne disease [58] that enters human cells by interaction through spike-like glycoproteins with angiotensin-converting enzyme type-2 (ACE2), a membranebound enzyme that is responsible for the hydrolysis of angiotensin-II into functional vasodilator angiotensin [59, 60] (Fig. 5). ACE2 is markedly expressed in epithelial cells of the lung, which provides excellent points of entry for
SARS-CoV-2 via respiratory droplets [61]. Respiratory droplets from nose and throats of COVID-19 patients are the primary route of transmission, which promoted the status of face mask in the fight against the pandemic [62].

Mutation in amino acid residues of D614G in SARS-CoV2 improves the affinity and efficiency of the virus uptake in relative to other influenza viruses and coronaviruses such as H5N1, H1N1, and MERS [63, 64]. Once SARS-CoV-2 enters the epithelial lining of the lung, replication occurs and damages the cells which eventually lead to death of cell (apoptosis) while inducing the release of pro-inflammatory cytokines and chemokines, such as interleukins (ILs) and interferons (IFs) in large quantities [65]. Subsequently, the
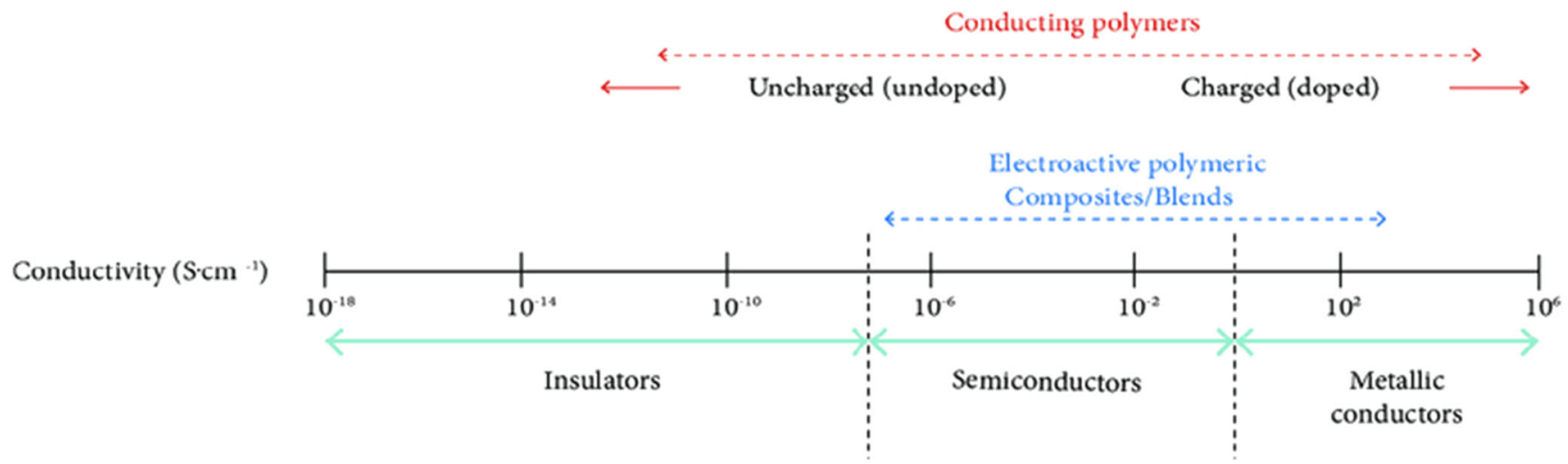

Fig. 4 Conductivity range measurement of CPs [13] 
(1)

Cytotoxic

effect

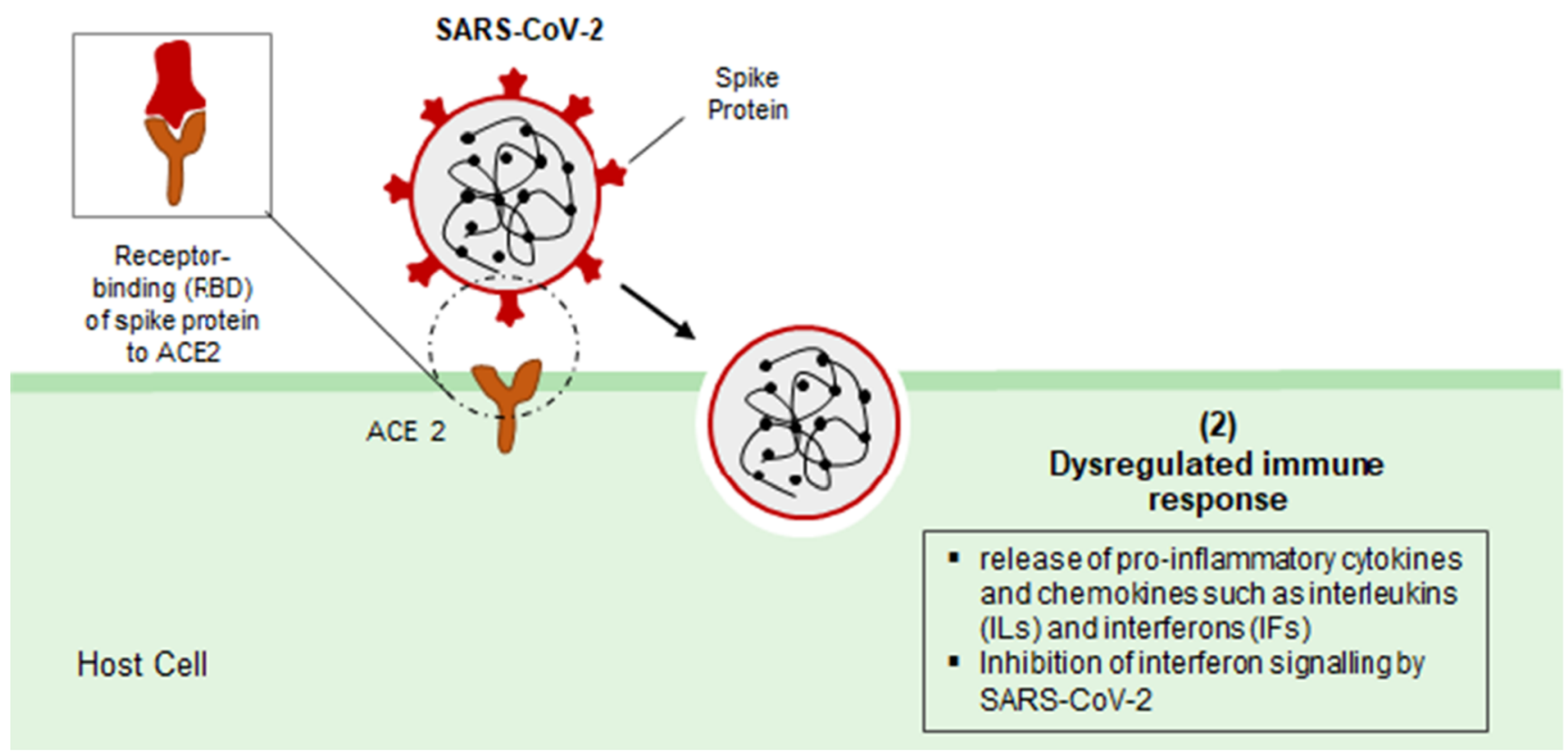

Fig. 5 Mechanism of SARS-CoV-2 enters host cells through interaction of its spike protein with the entry receptor ACE2. Proposed mechanisms for COVID-19 caused by infection with SARS-CoV-2 include (1) cytotoxic effect causing host cell death (apoptosis); (2) dysregulation of the immune response and hyper inflammation caused by inhibition of interferon signaling by the virus. The figure is adapted and modified from [73] absence of mucociliary clearance of epithelial lining in the lung leads to accumulation of mucus in alveoli air sacs that encourages bacterial growth and development of pneumonia [66]. Studies on the interplay between SARS-CoV-2 and type I IFNs confirmed that SARS-Cov-2 infection inhibits type I IFNs production and signaling which increases susceptibility of the host toward secondary bacterial infections $[67,68]$. The infections include bloodstream infections that are normally caused by coagulase-negative staphylococci, Acinetobacter baumannii, Escherichia coli, [69], Klebsiella pneumoniae, and Stenotrophomonas maltophilia [70]. Other viruses that caused respiratory diseases such as rhinovirus and influenza virus also show increased secondary invasion of the airway epithelium lining by pathogenic bacteria and worsening disease progression [71]. Bacterial infections may reciprocally enhance viral infection by limiting the activation of the nuclear factor kappa B (NF-kB) signaling pathway that negatively impacts host-immune response against viruses [72].

Viral respiratory diseases due to influenza viruses, rhinoviruses, and coronaviruses are commonly associated with adverse disease severity and fatalities [74]. Furthermore, secondary bacterial infections are more likely to happen in hospital settings (nosocomial infections) that can occur through inadequate air ventilation, transmission from health personnel, and from invasive indwelling medical devices such as catheters and mechanical ventilators [75]. Because ventilator-associated pneumonia (VAP) showed a very high prevalence ( $86 \%$ ) of nosocomial pneumonia [76, 77], this situation is highly relevant to critical COVID-19 patients who are monitored in intensive care units (ICU) that require mechanical ventilators for breathing support. Indeed, nosocomial infections are commonly observed in ICU patients that are infected with a respiratory virus [57].

Besides mechanical ventilators, personal protective equipment (PPE), such as gloves and gowns of healthcare personnel, poses the threat of nosocomial infections during patient care and handling [78]. Although preventive measure with antibiotics is a viable option, this measure could be counterproductive. Unrestrained administration of antibiotics leads to the emergence of antibiotic-resistant bacteria, such as methicillin-resistant Staphylococcus aureus (MRSA), vancomycin-resistant Enterococci (VRE), and carbapenemresistant Enterobacteriaceae (CRE) [79]. In fact, the current SARS-CoV-2 pandemic runs concurrently with the ongoing pandemic of antibiotic-resistant bacteria which exacerbates the issue of nosocomial infections [80]. One way to reduce the odds of nosocomial infections without depending on antibiotics is by developing potential antibacterial polymers that can be incorporated into indwelling medical devices (e.g.,

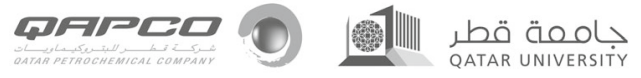


endotracheal tubes) and hospital PPE (e.g., mask or gown). For example, antimicrobial textiles are proven to play a vital role in neutralizing the threat of pathogens [81]. The formation of $S$. aureus biofilm on indwelling medical devices causes serious complications in hospitalized COVID-19 patients [82]. However, studies have shown that the formation of this biofilm can be minimized by coating the devices with CP [83]. An advantage of incorporating CP in indwelling medical devices and hospital PPE is that it could promote antimicrobial properties, even against antibiotic-resistant bacteria [84].

Based on previous studies [81, 83], it was speculated that the application of antimicrobial materials in PPE and indwelling medical devices could address nosocomial infections by disrupting bacterial transmission to COVID-19 patients. With promising antimicrobial properties, these functional materials could be potentially used to fabricate mask, glove, bandages, and hygienic products. Most polymers with intrinsic antimicrobial properties are positively charged, and most bacterial cell walls are negatively charged. Interaction between positively charged polymers and negatively charged cell membrane kill the bacterial cell. Polymeric antimicrobial agents possess the advantages of non-volatility, chemical stability, and lacking the capacity to penetrate the skin [85].

Our discussion on CPs as a component material for PPE and bed cloth is driven by the interest of antimicrobial polymers and its importance. Integrating CPs in PPE and bed cloth could make a difference in combating nosocomial infections in contaminated hospital environments. To date, there are no studies on the relationships between CPs and nosocomial infections. However, there are studies that explore the role of CPs in disrupting bacterial growth. As CPs, polyaniline (PANI), polypyrrole (PPy), and poly (3, 4-ethylenedioxythiophene) polystyrene sulfonate (PEDOT: PSS) have demonstrated the potency of their antimicrobial properties [86]. These intrinsically conducting polymers (ICP) are embedded in textiles due to their electrical conductivity [87].

\section{Antibacterial properties of conducting polymers}

Even in low concentrations, functionalized PANI (f-PANI) are potent enough to inhibit the growth of Gram-positive and Gram-negative pathogens such as wild-type Pseudomonas aeruginosa, Escherichia coli, and $S$. aureus. P. aeruginosa was fully eradicated after $15 \mathrm{~min}$ of exposure to poly (anilineco-3-aminobenzoic acid) (3ABAPANI). Similarly, S. aureus and $E$. coli were completely eradicated after being exposed to the same CP for $45 \mathrm{~min}$ and $180 \mathrm{~min}$, respectively. Inhibition of bacterial growth on brain heart infusion (BHI) plates was observed upon overnight incubation of E. coli and P. aeruginosa in the presence of f-PANI [84]. Apart from carrying the quality of antibacterial properties, PPy is also biodegradable, which is an advantageous quality when embedded in materials and textiles [88]. Furthermore, by grafting conducting polymer chains onto a polysaccharide-based biodegradable polymer such as chitosan (CS), the antibacterial activity of those copolymers could be improved. Cabuk et al. [89] showed that polyaniline-g-chitosan (PANI-g-CS), polypyrrole-g-chitosan (PPy-g-CS), and polythiophene-g-chitosan (PT-g-CS) copolymers enhanced antibacterial activity against $E$. faecalis and $S$. aureus compared to their homopolymer counterparts and CS backbones. The presence of these polymers into CS backbones promotes the sustainable release of cationic groups into the nutrient media for bacteria culture, which indirectly improved the antibacterial activity.

The positive charges along the backbone chains that are responsible for the antibacterial activity of PPy are produced via oxidative polymerization. One positive charge is formed with each three to five repeat units of PPy. This positive charge is counterbalanced by counterions (namely as dopants) in the polymerization solution that is embedded in the polymer matrix.

There are several possible antibacterial mechanisms of CP.

a) Via disruption of bacterial cell wall and membranes because of electrostatic contact between bacteria and polymers [81] (Fig. 6). Cationic antimicrobial compounds act to penetrate the anionic bacterial membranes. This action disrupts membrane integrity and interferes the process of cell proliferation, which eventually leads to cell death [90].

Theoretically, the structures of cell wall of Gram-negative and Gram-positive bacteria are dissimilar. Cell walls of Gramnegative bacteria have thinner layers of peptidoglycan (7-8 $\mathrm{nm}$ ) below the lipopolysaccharide layer. On the contrary, Gram-positive bacteria have thicker peptidoglycan on their cell wall $(20-80 \mathrm{~nm})$. Therefore, Gram-negative bacteria are surrounded by negatively charged lipopolysaccharides, which make them easily attracted to $\mathrm{CP}$ chains, such as PANI. The positive imino sites in PANI chains have a high affinity to negatively charged outer membrane of Gram-negative bacteria. These PANI chains anchor to bacterial cell walls at multiple locations. This process compromises the integrity of the outer membrane by changing the potential gradients across ion channels on bacterial cell walls. Gram-positive bacteria peptidoglycan layers are more rigid since they have linear polysaccharide chains that are cross-linked by short peptides. This characteristic reduces the anchoring capability of PANIs to the cell wall while making it more difficult for the dopant to penetrate the cells. Because of this exclusive structure, growth of Gram-positive bacteria is less compromised to that of Gram-negative bacteria [91].

b)Via production of hydrogen peroxide that causes the formation of hydroxyl radicals. These radicals could contribute to death of bacterial cell by impairing the biomolecule process, e.g., PANI [90]. 
a

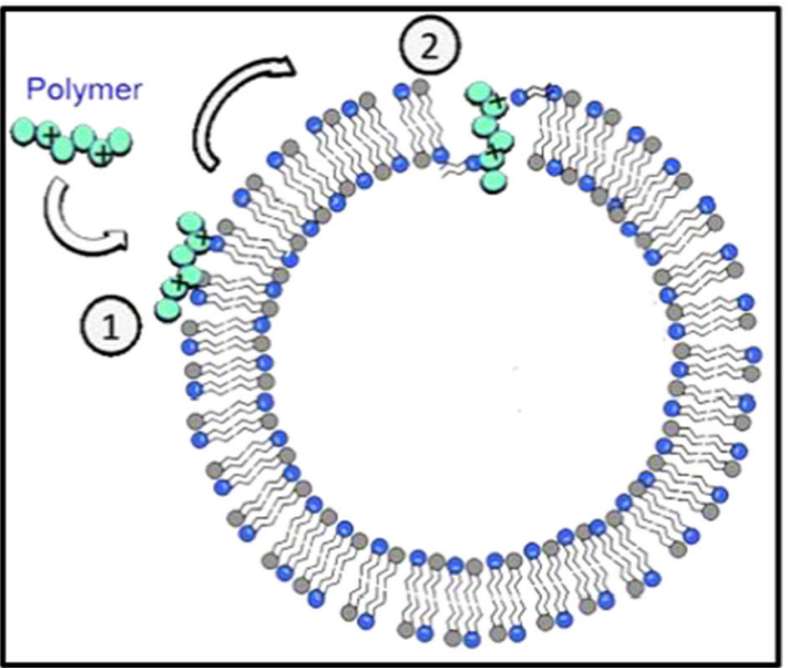

c

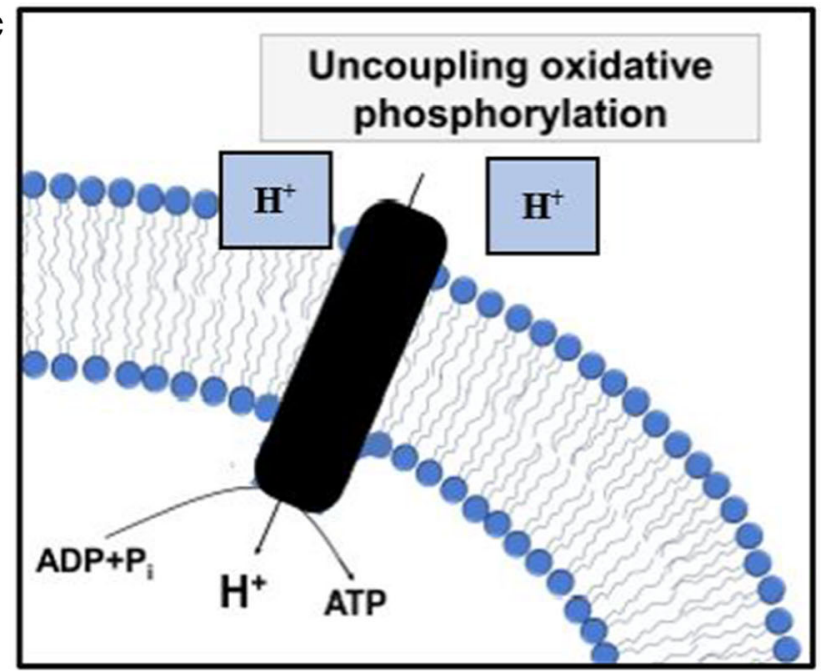

b

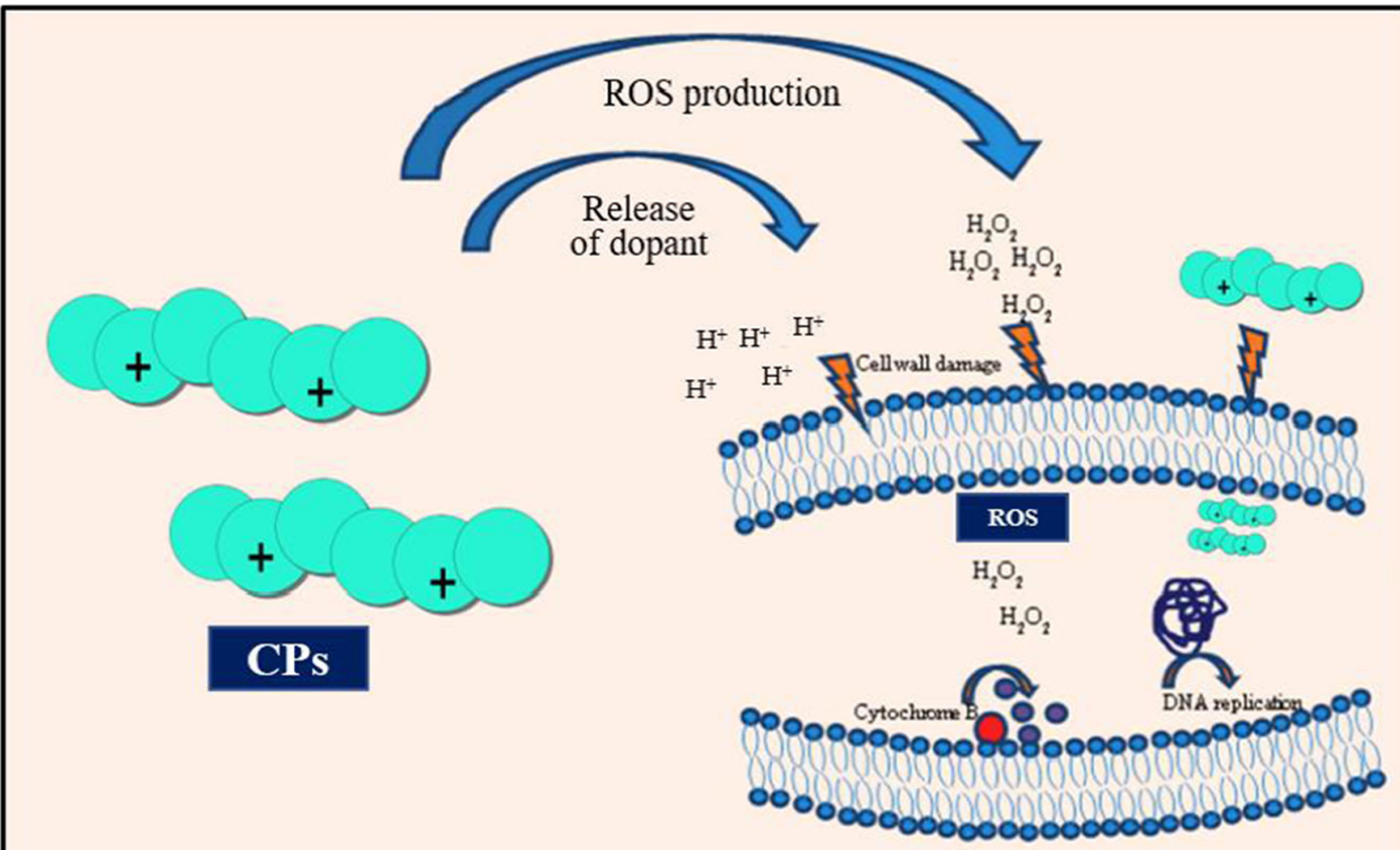

Bacterial cell wall

Fig. 6 General mechanisms of antibacterial activity of CPs. (A) Disruption of bacterial cell wall. (B) Production of ROS (from dopants) that contribute to the bacterial cell death. (C) Disruption of metabolic and respiratory machinery (e.g., ATP synthase). Figures are adapted and modified from [90, 93, 94]

This mechanism of bacterial cell death is also preceded by the release of reactive oxygen species (ROS), which impairs bacterial cell membranes, DNA, and proteins. The adhesion of bacteria to the polymers disrupts the native surface charge of bacterial cells, which leads to cell lysis total cell destruction [92].
c)Via uncoupling by targeting ATP synthase and disrupting the metabolic and respiratory machinery which causes acid stress, oxidative stress, and dysregulation of iron homeostasis [90].

Besides pristine polymers, it is also speculated that copolymers in the form of emeraldine salt are more effective against 
microbes compared to the same copolymers in emeraldine base forms [95]. $-\mathrm{COOH}$ acidic functional groups in the polymeric chain enhance the antibacterial efficacy of the copolymer, theoretically by the reaction of the acidic dopants on the polymeric chains with bacteria, which eventually inhibits the growth or eliminating the bacteria altogether [95]. Another possible reason could be due to the electrostatic adherence between copolymer molecules and bacteria that results in opposing polarity charges. This discrepancy in charges breaks down bacterial cell membranes, which leads to the fatal leakage of cytoplasm in bacteria [96].

\section{Conducting polymers for PPE}

CPs can be integrated into PPE by embedding it into the fibers of non-woven fabrics or coating the fabrics. For non-woven fabrics, several techniques can spin the fibers, such as solution spinning, melt spinning, and electrospinning. Meanwhile, in situ polymerization, melt mixing, and solvent methods are common techniques to coat the fabrics with CPs.

\subsection{Fibers fabrication of non-woven fabrics}

Non-woven fabrics is a fabric-like material, made from fibers that are entangled or bonded together through mechanical, chemical, or thermal means. These fabrics can be found in agriculture, clothes, automotive, household items, stationery, and many more [97]. The fibers need to be spun to produce the non-woven fabrics. The polymer that will be spun into fiber needs to be in a liquid or semi-liquid state by either dissolving it in a solvent or melting it. It is extruded through a small orifice of a spinneret, which then hardens to form a fiber or filament. This process is called spinning. The three common spinning techniques are solution spinning, melt spinning, and electrospinning. The CPs can be incorporated into the fibers by adding it in the polymer solutions or melts.

\subsubsection{Solution spinning}

Solution spinning is one of the oldest techniques in preparing man-made fibers. It was introduced in the late nineteenth century. It is called a solution technique because the polymer in this technique is dissolved in a solvent prior to the spinning process. This technique can be divided into wet spinning and dry spinning (Fig. 7).

For wet spinning, the machine is assembled by placing the spinneret in the spin bath, which is usually filled with water. The polymer is spun by extruding it into the water. During this process, the solvent in the extrudates (fibers) is discarded and diffused out into the water. Then, the fibers are rinsed with water and dried. For dry spinning, instead of spin bath, the polymer is extruded into a heated column, called the evaporation chamber. The heat evaporates the solvent in the fibers.

A study by Lu et al. [98] is an excellent example in utilizing wet spinning technique to manufacture CPs-embedded fibers. A high-performance stretchable conductive composite fibers were wet spun by combining surface-modified silver nanowires (AgNW) with polyurethane (PU). The surface of AgNW was coated with polyethylene glycol methyl ether (mPEG). This surface modification improved the solubility of $\mathrm{AgNW}$ in $\mathrm{PU}$ since both polymers have similar solubility parameters, thus promoting homogeneous dispersion of AgNW in the PU matrix.

Dry spinning technique is also used in the manufacturing of CPs fibers. Tian et al. [99] used this technique to produce continuous graphene fibers (GFs) and compared their result with GFs that were with the wet spinning technique. They found that dry spun GFs had better toughness $\left(19.12 \mathrm{MJ} / \mathrm{m}^{3}\right)$ compared to wet spun GFs. However, its electrical conductivity was considerably low $\left(1.32 \times 10^{4} \mathrm{~S} / \mathrm{m}\right)$ compared to that of wet spun GFs $\left(80.0 \times 10^{4} \mathrm{~S} / \mathrm{m}\right)$.

\subsubsection{Melt spinning}

With no solvent required and a high spinning rate, melt spinning is the most economical method. During spinning, a viscous melted polymer is extruded through the spinneret and simultaneously blasted with cold air to solidify the molten polymer into fibers. The fibers are then either wound onto bobbins or treated with a finishing product.

However, melt spinning is less popular when it comes to spinning CPs into fibers due to the complexity of the process. Several parameters need to be optimized to spin the fiber, such as temperature profile, throughput, take-off, and winding speeds [100]. Melt-spun fibers of PANI/polypropylene blends by Kim et al. [101] showed low conductivity because of the inhomogeneous distribution of PANI in the fiber. This inhomogeneous distribution caused poor electrical conductivity due to the disconnections between PANI. Lim et al. [102] manufactured highly conductive silver fibers by embedding carbon nanotubes in the fibers. They found that the addition of carbon nanotube in the formulation acted like bridges between the disconnected silver in the fibers, thus promoting high electrical conductivity.

\subsubsection{Electrospinning}

Unlike the spinning techniques mentioned previously, electrospinning techniques can produce very fine fibers, with diameters in the range of sub-micrometer or nanometer [103]. This technique is an extension of solution spinning and melt spinning, which employs electrostatic attraction of charges during the manufacturing process [104]. The electrospinning setup comprises a syringe with needle, direct current (DC) power supply, a syringe pump, and grounded metal collector 


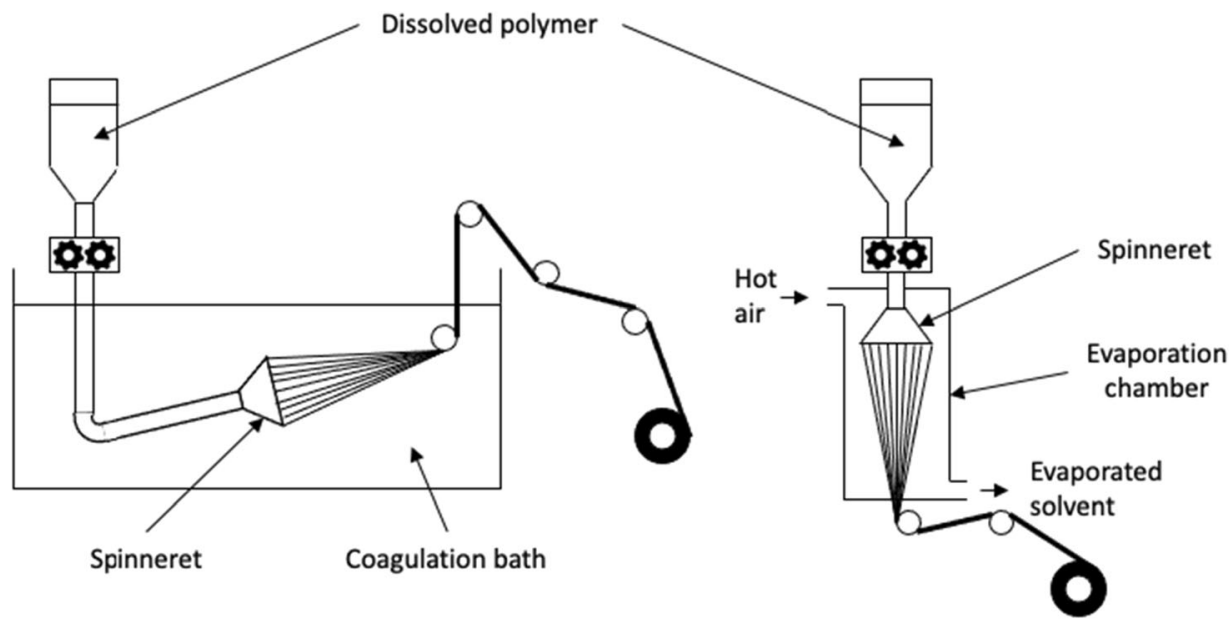

a) Wet spinning b) Dry spinning

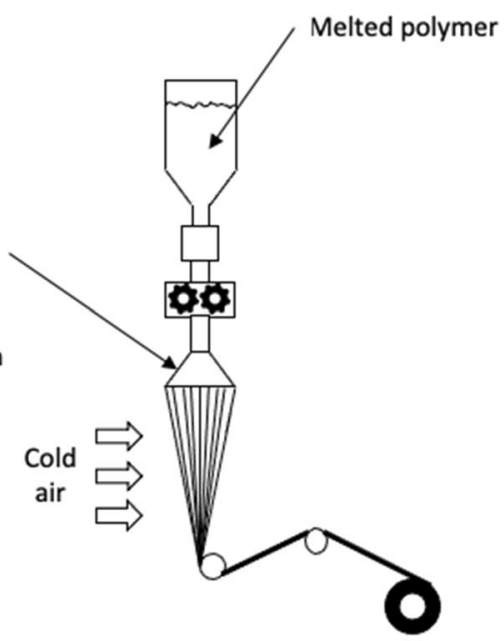

Fig. 7 Diagram of (a) wet spinning, (b) dry spinning, and (c) melt spinning

(Fig. 8). The polymer solutions or melts are introduced into the syringe. The hollow needle of the syringe is connected to the positive terminal of a DC power supply, while the negative terminal is connected to a metal collector [105]. During the manufacturing process, high voltage is supplied to the hollow needle which causes the polymer to bypass its surface tension. The polymer assumes a cone-like structure, called the Taylor cone, and the drops are ejected at the tip of the needle [106]. The ejected polymer will be solidified into fibers and collected on a grounded collector as a mesh or scaffold [104].
Castagna et al. [107] successfully electrospun ultrathin PANI nanofibers $(65 \pm 14 \mathrm{~nm})$ by blending PANI with polymethyl methacrylate (PMMA). They also increased the amount of PANI in the PMMA blend of up to $2: 1$ ratio (w/w), which produced highly uniform fibers. Another study by Bessaire et al. [108] on PEDOT: PPS fiber formation found that humidity level plays an important role during the electrospinning process. They noticed that by increasing the relative humidity $(\mathrm{RH})$ from $7 \% \mathrm{RH}$ to $42 \% \mathrm{RH}$, the average diameter of the fibers decreased from 157 to $105 \mathrm{~nm}$. Beads

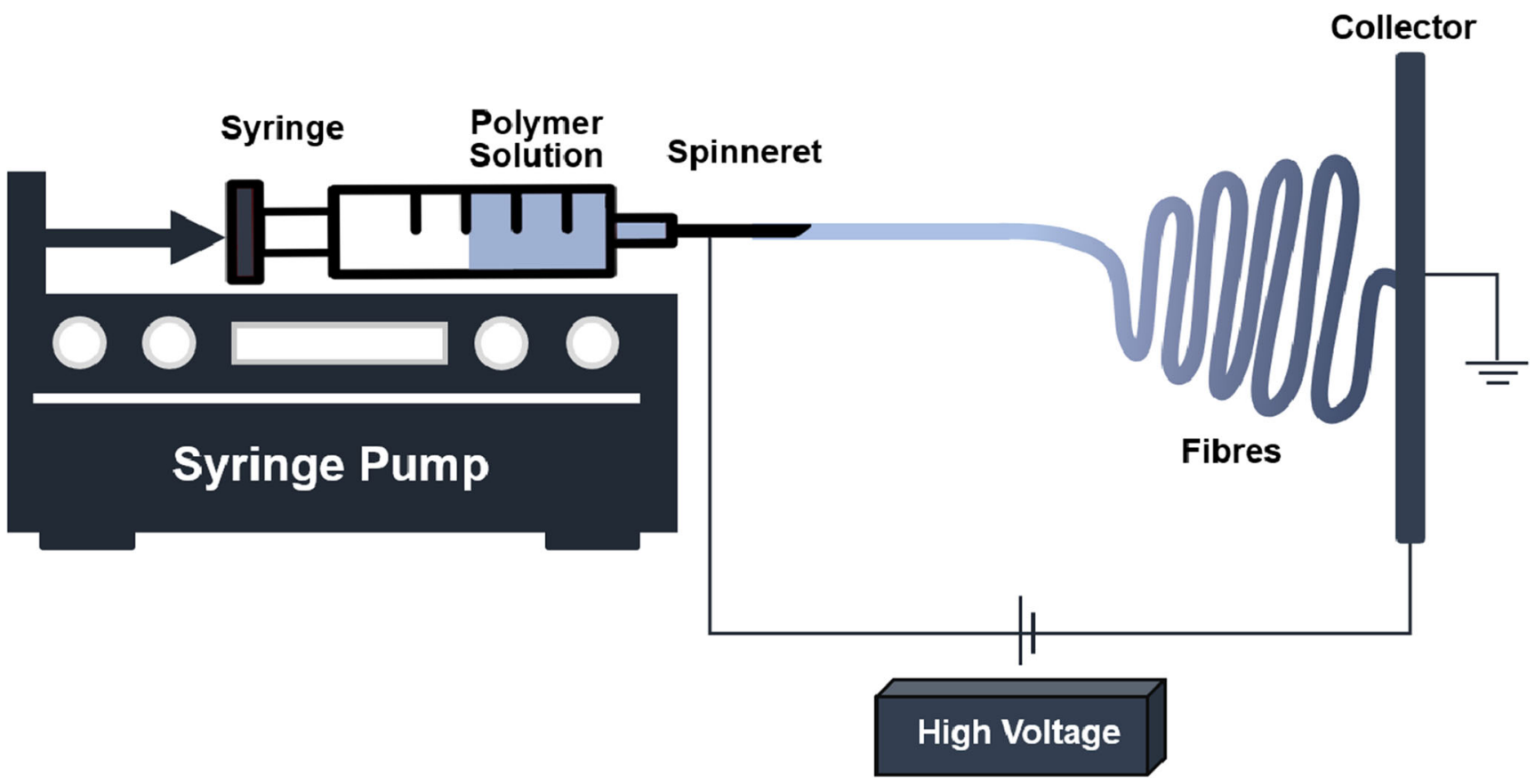

Fig. 8 Depiction of electrospinning setup 
formation was also observed with each increment in the humidity level.

\subsection{CPs coating on fabrics}

CPs can also be incorporated into PPE by coating the readymade fabric with the polymer. An example of employed CPs in this scenario is graphene-based CPs. The graphene's large surface area presents more active sites for electrochemical composites in electrochemical reactions [109]. Coating of PPE fabrics with graphene-based CPs is the technique in focus for this section. However, there are other CPs that could be potentially employed with these techniques, such as PPy, PEDOT-PSS, PANI, PA, PT, PPP, and PPV [100]. In situ polymerization, melt mixing, and solvent methods are the common techniques in this process.

\subsubsection{In situ polymerization}

In this technique, graphene is mixed with monomer with the occasional addition of suitable catalysts. The polymerization process is initiated by the application of heat treatment or radiation [110]. This technique produces the beneficial outcome of high homogeneity of graphene particle dispersion. On the flipside, there is a rapid viscosity increment with this technique, which lowers the dispersion degree of the graphene [111]. Sometimes, solvents are used in which additional solvent removal steps are required [112].

\subsubsection{Melt mixing}

Melt mixing or compounding is an environmentally friendly and cost-effective technique since no solvent is required [111]. Graphene and polymer matrix are mixed and melted together while applying high shear blending at high temperature [113]. This technique is mainly used in the fabrication of thermoplastic composites. The disadvantage of this technique is similar with in situ polymerization technique, which is high graphene content in the composites due to gradual increase in viscosity [111].

\subsubsection{Solvent method}

Solvent method is known as the simplest and most frequently used technique when compared to the previously mentioned techniques. No specialized equipment is required for this technique. Graphene-based CPs are prepared by dissolving the polymer in solvent, followed by the addition of graphene. Graphene sheets need to be functionalized to reduce solubility and dispersity, and aggregation problems in different solvents [113].

Solvent plays an important role in this process and should be carefully selected. It should not degrade the polymer, easily dissolve the polymer, has good graphene dispersion property, and can be easily removed from the system [111]. However, this technique is not environmentally friendly since harmful solvents are necessary in this technique [114].

\section{Conclusion}

The emergence of the novel coronavirus SARS-CoV-2 has taken the world by storm due to its alarming infection rate. Currently, there is no effective strategy to contain the spread of the virus and its subsequent infection. COVID-19 patients are vulnerable to secondary bacterial infections that could be potentially transmitted from PPE or medical devices. One approach to minimize the possibility of secondary bacterial infections is by incorporating CPs into PPE materials. CPs can be tailored with various types of polymers with a broad spectrum of properties. By tuning the dopant, which is also the conductive agent, we can fit it to the desired properties. This major advantage paves the way for a greater exploration of CPs as a viable functional material in the battle against the COVID-19 pandemic. Besides PPE, CPs could also be applied in medical devices, for example, CPs-coated endotracheal tubes to prevent ventilator-associated pneumonia infections that are acquired in hospital settings (nosocomial infection). Despite their potential, more laboratory and clinical studies are required to evaluate the antibacterial properties of CPs. For example, studies of CPs-coated PPE may be performed on $K$. pneumoniae that is prevalent among COVID-19 patients. Further investigations are warranted to optimize the incorporation techniques of CPs into PPE and medical devices. In this review, several processing techniques to produce antibacterial PPE materials were presented, and they are embedding CP into the fibers of non-woven fabric, or coating of the fabric's surface with CP. Although the antibacterial mechanisms of the CPs were discussed, there are still gaps in the bigger picture of CPs' antibacterial properties since some aforementioned mechanisms are not applicable to other CPs. Even though it was proven that CPs could interrupt the growth of bacteria by disrupting bacterial cell walls, extensive studies are still needed to reveal the nature of structural arrangement and their composition in fighting bacterial infections. Collectively, this review provides insights into the application of CPs as potential functional materials to ward off secondary bacterial infection, especially among COVID19 patients.

Acknowledgments We would like to thank Nazreen Che Roslan, Muhammad Faiz Aizamddin, Ayu Natasha Ayub and Dania Adila

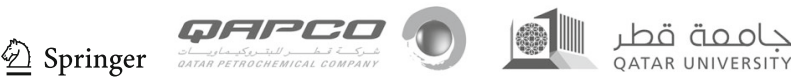


Ahmad Ruzaidi for the contribution in illustrating the figures and some technical arrangements of the manuscript.

Authors' contributions The manuscript was written through the equal contributions of all authors. All authors have given approval to the final version of the manuscript.

Funding The authors acknowledge the support given by Universiti Teknologi MARA Malaysia (600-IRMI 5/3/GIP (010/2019), International Islamic University Malaysia (Internal grant RIGS 16-2880452), and Universiti Sains Malaysia (Grant ID: 304.CDADAH.6315221).

\section{Declarations}

Conflict of interest The authors declare that they have no conflict of interest.

\section{References}

1. Y. Ding, M.A. Invernale, G.A. Sotzing, Conductivity trends of pedot-pss impregnated fabric and the effect of conductivity on electrochromic textile. ACS Appl. Mater. Interfaces 2, 15881593 (2010)

2. C. Zhang, M.H. Hsieh, S.Y. Wu, S.H. Li, J. Wu, S.M. Liu, H.J. Wei, R.D. Weisel, H.W. Sung, R.K. Li, A self-doping conductive polymer hydrogel that can restore electrical impulse propagation at myocardial infarct to prevent cardiac arrhythmia and preserve ventricular function. Biomaterials. 231, 119672 (2020)

3. K. Ashtari, H. Nazari, H. Ko, P. Tebon, M. Akhshik, M. Akbari, S.N. Alhosseini, M. Mozafari, B. Mehravi, M. Soleimani, R. Ardehali, M. Ebrahimi Warkiani, S. Ahadian, A. Khademhosseini, Electrically conductive nanomaterials for cardiac tissue engineering. Adv. Drug Deliv. Rev. 144, 162-179 (2019)

4. A. Talebi, S. Labbaf, F. Karimzadeh, A conductive film of chitosan-polycaprolcatone-polypyrrole with potential in heart patch application. Polym. Test. 75, 254-261 (2019)

5. L. Wang, Y. Wu, T. Hu, B. Guo, P.X. Ma, Electrospun conductive nanofibrous scaffolds for engineering cardiac tissue and 3D bioactuators. Acta Biomater. 59, 68-81 (2017)

6. D.S. Morais, R.M. Guedes, M.A. Lopes, Antimicrobial approaches for textiles: From research to market. Mater. 9, 498 (2016)

7. M. Mashkour, M. Rahimnejad, M. Mashkour, F. Soavi, Electropolymerized polyaniline modified conductive bacterial cellulose anode for supercapacitive microbial fuel cells and studying the role of anodic biofilm in the capacitive behavior. J. Power Sources 478, 228822 (2020)

8. X. Yang, P. Xia, Y. Zhang, S. Lian, H. Li, G. Zhu, P. Wang, Photothermal nano-antibiotic for effective treatment of multidrug-resistant bacterial infection. ACS Appl. Bio Mater. 3, 5395-5406 (2020)

9. S. Saidin, M.A. Jumat, N.A.A. Mohd Amin, A.S. Saleh AlHammadi, Organic and inorganic antibacterial approaches in combating bacterial infection for biomedical application. Mater. Sci. Eng. C 118, 111382 (2021)

10. R.S. Norouzian, M.M. Lakouraj, Polyaniline-thiacalix[4] arene metallopolymer, self-doped, and externally doped conductive polymers. Prog. Org. Coat. 146, 105731 (2020)

11. S.N.I. Omar, Z.Z. Ariffin, A. Zakaria, M.F. Safian, M.I.A. Halim, R. Ramli, Z.M. Sofian, M.F. Zulkifli, M.F. Aizamddin, et al., Electrically conductive fabric coated with polyaniline: physicochemical characterization and antibacterial assessment. Emergent Mater 3, 469-477 (2020)

12. S.N.I. Omar, Z.Z. Ariffin, R.M. Akhir, M.I.A. Halim, R. Ramli, M.M. Mahat, Electrically conductive polyester fabrics embedded polyaniline. Int. J. Eng. Technol 7, 524-528 (2018)

13. R. Balint, N.J. Cassidy, S.H. Cartmell, Conductive polymers: towards a smart biomaterial for tissue engineering. Acta Biomater. 10, 2341-2353 (2014)

14. A. Ehsani, M. Bigdeloo, F. Assefi, M. Kiamehr, R. Alizadeh, Ternary nanocomposite of conductive polymer/chitosan biopolymer/metal organic framework: Synthesis, characterization and electrochemical performance as effective electrode materials in pseudocapacitors. Inorg. Chem. Commun. 115, 107885 (2020)

15. W. Liu, M. Li, G. Jiang, G. Li, J. Zhu, M. Xiao, Y. Zhu, R. Gao, A. $\mathrm{Yu}$, et al., Graphene quantum dots-based advanced electrode materials: design, synthesis and their applications in electrochemical energy storage and electrocatalysis. Adv. Energy Mater. 10, 1-49 (2020)

16. H. Mohammad Shiri, A. Ehsani, M. Jalali Khales, Electrochemical synthesis of $\mathrm{Sm} 2 \mathrm{O} 3$ nanoparticles: application in conductive polymer composite films for supercapacitors. J. Colloid Interface Sci. 505, 940-946 (2017)

17. Riquelme RS, Fabrication, characterization and applications of highly conductive wet-spun PEDOT: PSS Fibers. (University of Kentucky, 2020)

18. L.V. Kayser, D.J. Lipomi, Stretchable conductive polymers and composites based on PEDOT and PEDOT: PSS. Adv. Mater. 31, $1-13(2019)$

19. X. Wang, A.K.K. Kyaw, C. Yin, F. Wang, Q. Zhu, T. Tang, P.I. Yee, J. Xu, Enhancement of thermoelectric performance of PEDOT: PSS films by post-treatment with a superacid. RSC Adv. 8, 18334-18340 (2018)

20. Y. Liu, J. Feng, An attempt towards fabricating reduced graphene oxide composites with traditional polymer processing techniques by adding chemical reduction agents. Compos. Sci. Technol. 140, 16-22 (2017)

21. M.M. Mahat, D. Mawad, G.W. Nelson, S. Fearn, R.G. Palgrave, D.J. Payne, M.M. Stevens, Elucidating the deprotonation of polyaniline films by X-ray photoelectron spectroscopy. J. Mater. Chem. C 3, 7180-7186 (2015)

22. A. Inoue, H. Yuk, B. Lu, X. Zhao, Strong adhesion of wet conducting polymers on diverse substrates. Sci. Adv. 6, 1-10 (2020)

23. E. Bihar, T. Roberts, Y. Zhang, E. Ismailova, T. Hervé, G.G. Malliaras, J.B. De Graaf, S. Inal, M. Saadaoui, Fully printed allpolymer tattoo/textile electronics for electromyography. Flex. Print. Electron. 3, 034004 (2018)

24. N. Zhang, F. Huang, S. Zhao, X. Lv, Y. Zhou, S. Xiang, S. Xu, Y. Li, G. Chen, C. Tao, Y. Nie, J. Chen, X. Fan, Photo-rechargeable fabrics as sustainable and robust power sources for wearable bioelectronics. Matter. 2, 1260-1269 (2020)

25. S.N.I. Omar, Z.Z. Ariffin, R.A.M. Akhir, D.N.A. Shri, M.I.A. Halim, M.F. Safian, H.H. Azman, R. Ramli, M.M. Mahat, Polyaniline (PANI) fabric doped p-toluene sulfonic acid (pTSA) with anti-infection properties. Mater. Today Proc. 16, 1994-2002 (2019)

26. B.L. Gray, Polymer nanocomposites for flexible and wearable fluidic and biomedical microdevices. 2018 IEEE 13th Nanotechnol. Mater. Devices Conf. 1-2 (2019)

27. J. Zhu, H. Cheng, Recent development of flexible and stretchable antennas for bio-integrated electronics. Sensors (Switzerland). 18, $1-22(2018)$

28. M.M. Mahat, M.F. Aizamddin, N.C. Roslan, M.A. Kamarudin, S.N.I. Omar, M.I.A. Halim, M.M. Mazo, Conductivity, morphology and thermal studies of polyaniline fabrics. Aust. J. Mech. Eng. 9, $137-150(2020)$ 
29. N.C. Roslan, M.F. Aizamddin, S.N.I. Omar, N.A. Jani, M.I.A. Halim, Z.Z. Ariffin, M.M. Mahat, Morphological and conductivity studies of polyaniline fabric doped phosphoric acid. Malaysian J. Anal. Sci. 24, 698-706 (2020)

30. M.F. Aizamddin, N.C. Roslan, M.A. Kamarudin, S.N.I. Omar, M.F. Safian, M.I.A. Halim, M.M. Mahat, Study of conductivity and thermal properties of polyaniline doped with p-toluene sulfonic acid. Malaysian J. Anal. Sci. 24, 413-421 (2020)

31. M.F. Aizamddin, M.M. Mahat, M.A. Nawawi, Morphological, structural and electrochemical studies of conductive polyaniline coated polyester fabrics., in Int. Exch. Innov. Conf. Eng. Sci., (2019)

32. J. Ouyang, "Secondary doping" methods to significantly enhance the conductivity of PEDOT: PSS for its application as transparent electrode of optoelectronic devices. Displays. 34, 423-436 (2013)

33. T.H. Le, Y. Kim, H. Yoon, Electrical and electrochemical properties of conducting polymers. Polymers (Basel). 9, 150 (2017)

34. X. Guo, A. Facchetti, The journey of conducting polymers from discovery to application. Nat. Mater. 19, 922-928 (2020)

35. M. Bharti, A. Singh, S. Samanta, D.K. Aswal, Conductive polymers for thermoelectric power generation. Prog. Mater. Sci. 93, 270-310 (2018)

36. D. Mawad, C. Mansfield, A. Lauto, F. Perbellini, G.W. Nelson, J. Tonkin, S.O. Bello, D.J. Carrad, A.P. Micolich, M.M. Mahat, J. Furman, D. Payne, A.R. Lyon, J.J. Gooding, S.E. Harding, C.M. Terracciano, M.M. Stevens, A conducting polymer with enhanced electronic stability applied in cardiac models. Sci. Adv. 2, e1601007 (2016)

37. D. Mawad, A. Artzy-Schnirman, J. Tonkin, J. Ramos, S. Inal, M.M. Mahat, N. Darwish, L. Zwi-Dantsis, G.G. Malliaras, J.J. Gooding, A. Lauto, M.M. Stevens, Electroconductive hydrogel based on functional poly (ethylenedioxy thiophene). Chem. Mater. 28, 6080-6088 (2016)

38. C.O. Baker, X. Huang, W. Nelson, R.B. Kaner, Polyaniline nanofibers: broadening applications for conducting polymers. Chem. Soc. Rev. 46, 1510-1525 (2017)

39. A.M. Grancarić, I. Jerković, V. Koncar, C. Cochrane, F.M. Kelly, D. Soulat, X. Legrand, Conductive polymers for smart textile applications. J. Ind. Text. 48, 612-642 (2018)

40. K.H. Hong, K.W. Oh, T.J. Kang, Preparation and properties of electrically conducting textiles by in situ polymerization of poly(3, 4-ethylenedioxythiophene). J. Appl. Polym. Sci. 97, 1326-1332 (2005)

41. G.A. Snook, P. Kao, A.S. Best, Conducting-polymer-based supercapacitor devices and electrodes. J. Power Sources 196, 1$12(2011)$

42. Y. Xia, S. Dai, Review on applications of PEDOTs and PEDOT: PSS in perovskite solar cells. J. Mater. Sci. Mater. Electron. (2020)

43. Y. Wen, J. Xu, Scientific importance of water-processable PEDOT-PSS and preparation, challenge and new application in sensors of its film electrode: a review. J. Polym. Sci. Part A Polym. Chem. 55, 1121-1150 (2017)

44. Z. Fan, J. Ouyang, Thermoelectric properties of PEDOT: PSS. Adv. Electron. Mater. 5, 1800769 (2019)

45. N.K. Jangid, N.P.S. Chauhan, K. Meghwal, R. Ameta, P.B. Punjabi, A review : conducting polymers and their applications. Res. J. Pharm., Biol. Chem. Sci. 5, 383-412 (2014)

46. X. Fan, W. Nie, H. Tsai, N. Wang, H. Huang, Y. Cheng, R. Wen, L. Ma, F. Yan, et al., PEDOT: PSS for flexible and stretchable electronics: modifications, strategies, and applications. Adv. Sci. 6, 1900813 (2019)

47. G.B. Tseghai, D.A. Mengistie, B. Malengier, K.A. Fante, L. Van Langenhove, PEDOT:PSS-based conductive textiles and their applications. Sensors. 20, 1881 (2020)
48. D.L. Gochnauer, T.H. Gilani, Conduction mechanism in electrically conducting polymers. Am. J. Undergrad. Res. 14, 49-56 (2018)

49. M.Y. Teo, N. Kim, S. Kee, B.S. Kim, G. Kim, S. Hong, S. Jung, K. Lee, Highly stretchable and highly conductive PEDOT: PSS/ ionic liquid composite transparent electrodes for solution-processed stretchable electronics. ACS Appl. Mater. Interfaces 9, 819-826 American Chemical Society (2017)

50. L.V. Lingstedt, M. Ghittorelli, H. Lu, D.A. Koutsouras, T. Marszalek, F. Torricelli, N.I. Crăciun, P. Gkoupidenis, P.W.M. Blom, Effect of DMSO solvent treatments on the performance of PEDOT: PSS based organic electrochemical transistors. Adv. Electron. Mater. 5, 1-8 (2019)

51. Y.Y. Lee, G.M. Choi, S.M. Lim, J.Y. Cho, I.S. Choi, K.T. Nam, Y.C. Joo, Growth mechanism of strain-dependent morphological change in PEDOT: PSS Films. Sci. Rep. 6, 25332 (2016)

52. J. Chen, Q. Yu, X. Cui, M. Dong, J. Zhang, C. Wang, J. Fan, Y. Zhu, Z. Guo, An overview of stretchable strain sensors from conductive polymer nanocomposites. J. Mater. Chem. C 7, 11710 11730 (2019)

53. D. Jucius, A. Lazauskas, V. Grigaliknas, R. Gudaitis, A. Guobiene, I. Prosycevas, B. Abakeviciene, M. Andrulevicius, Structure and properties of dual-doped PEDOT: PSS multilayer films. Mater. Res. 22, e20190134 (2019)

54. M.N. Gueye, A. Carella, J. Faure-Vincent, R. Demadrille, J.-P. Simonato, Progress in understanding structure and transport properties of PEDOT-based materials: a critical review. Prog. Mater. Sci. 108, 100616 (2020)

55. WHO WHO, WHO Director-General's opening remarks at the media briefing on COVID-19., 2020, https://www.who.int/ director-general/speeches/detail/who-director-general-s-openingremarks-at-the-media-briefing-on-covid-19 Accessed 11 March 2020

56. WHO, WHO Coronavirus Disease (COVID-19) Dashboard., 2020, https://covid19.who.int Accessed 28 December 2020

57. F. Zhou, T. Yu, R. Du, G. Fan, Y. Liu, Z. Liu, J. Xiang, Y. Wang, B. Song, et al., Clinical course and risk factors for mortality of adult inpatients with COVID-19 in Wuhan, China: a retrospective cohort study. Lancet 395, 1054-1062 (2020)

58. L. Morawska, J. Cao, Airborne transmission of SARS-CoV-2: the world should face the reality. Environ. Int. 139, 105730 (2020)

59. J. Lan, J. Ge, J. Yu, S. Shan, H. Zhou, S. Fan, Q. Zhang, X. Shi, Q. Wang, L. Zhang, X. Wang, Structure of the SARS-CoV-2 spike receptor-binding domain bound to the ACE2 receptor. Nature. 581, 215-220 (2020)

60. J. Yang, S.J.L. Petitjean, M. Koehler, Q. Zhang, A.C. Dumitru, W. Chen, S. Derclaye, S.P. Vincent, P. Soumillion, D. Alsteens, Molecular interaction and inhibition of SARS-CoV-2 binding to the ACE2 receptor. Nat. Commun. 11, 4541 (2020)

61. I. Hamming, W. Timens, M.L.C. Bulthuis, A.T. Lely, G.J. Navis, H. van Goor, Tissue distribution of ACE2 protein, the functional receptor for SARS coronavirus. A first step in understanding SARS pathogenesis. J. Pathol. 203, 631-637 (2004)

62. J.F.W. Chan, S. Yuan, K.H. Kok, K.K.W. To, H. Chu, J. Yang, F. Xing, J. Liu, C.C.Y. Yip, et al., A familial cluster of pneumonia associated with the 2019 novel coronavirus indicating person-toperson transmission: a study of a family cluster. Lancet. 395, 514 $523(2020)$

63. S. Isabel, L. Graña-Miraglia, J.M. Gutierrez, C. BundalovicTorma, H.E. Groves, M.R. Isabel, A.R. Eshaghi, S.N. Patel, J.B. Gubbay, T. Poutanen, D.S. Guttman, S.M. Poutanen, Evolutionary and structural analyses of SARS-CoV-2 D614G spike protein mutation now documented worldwide. Sci. Rep. 10, 14031 (2020)

64. L. Zhang, C.B. Jackson, H. Mou, A. Ojha, H. Peng, B.D. Quinlan, E.S. Rangarajan, A. Pan, A. Vanderheiden, M.S. Suthar, W. Li, T. 
Izard, C. Rader, M. Farzan, H. Choe, SARS-CoV-2 spike-protein D614G mutation increases virion spike density and infectivity. Nat. Commun. 11, 6013 (2020)

65. M. Yang, Cell pyroptosis, a potential pathogenic mechanism of 2019-nCoV infection. SSRN Electron. J. (2020)

66. M. Koparal, E. Kurt, E.E. Altuntas, F. Dogan, Assessment of mucociliary clearance as an indicator of nasal function in patients with COVID-19: a cross-sectional study. Eur. Arch. Oto-RhinoLaryngol. (2020)

67. H. Xia, Z. Cao, X. Xie, X. Zhang, J.Y.C. Chen, H. Wang, V.D. Menachery, R. Rajsbaum, P.Y. Shi, Evasion of type i interferon by SARS-CoV-2. Cell Rep. 33, 108234 (2020)

68. M.S. Ribero, N. Jouvenet, M. Dreux, S., Nisole, Interplay between SARS-CoV-2 and the type I interferon response. PLoS Pathog. 16, e1008737 (2020)

69. M. Ripa, L. Galli, A. Poli, C. Oltolini, V. Spagnuolo, A. Mastrangelo, C. Muccini, G. Monti, G. De Luca, et al., Secondary infections in patients hospitalized with COVID-19: incidence and predictive factors. Clin. Microbiol. Infect. (2020)

70. J. Li, J. Wang, Y. Yang, P. Cai, J. Cao, X. Cai, Y. Zhang, Etiology and antimicrobial resistance of secondary bacterial infections in patients hospitalized with COVID-19 in Wuhan, China: a retrospective analysis. Antimicrob. Resist. Infect. Control 9, 153 (2020)

71. A.A.T.M. Bosch, G. Biesbroek, K. Trzcinski, E.A.M. Sanders, D. Bogaert, Viral and bacterial interactions in the upper respiratory tract. PLoS Pathog. 9, e1003057 (2013)

72. R. Kircheis, E. Haasbach, D. Lueftenegger, W.T. Heyken, M. Ocker, O. Planz, NF-kB pathway as a potential target for treatment of critical stage COVID-19 patients. Front. Immunol. 11, 3446 (2020)

73. A. Gupta, M.V. Madhavan, K. Sehgal, N. Nair, S. Mahajan, T.S. Sehrawat, B. Bikdeli, N. Ahluwalia, J.C. Ausiello, E.Y. Wan, D.E. Freedberg, A.J. Kirtane, S.A. Parikh, M.S. Maurer, A.S. Nordvig, D. Accili, J.M. Bathon, S. Mohan, K.A. Bauer, M.B. Leon, H.M. Krumholz, N. Uriel, M.R. Mehra, M.S.V. Elkind, G.W. Stone, A. Schwartz, D.D. Ho, J.P. Bilezikian, D.W. Landry, Extrapulmonary manifestations of COVID-19. Nat. Med. 26, 1017-1032 (2020)

74. D.E. Morris, D.W. Cleary, S.C. Clarke, Secondary bacterial infections associated with influenza pandemics. In Front. Microbiol. (2017)

75. Y. Chander, R. Rai, Hospital Acquired Infection. Med. J. Armed Forces India. 54, 179-181 (1998)

76. J.D. Hunter, Ventilator associated pneumonia. BMJ. 344, e3325 (2012)

77. H.A. Khan, F.K. Baig, R. Mehboob, Nosocomial infections: Epidemiology, prevention, control and surveillance. Asian Pac. J. Trop. Biomed. 7, 478-482 (2017)

78. D.J. Morgan, E. Rogawski, K.A. Thom, J.K. Johnson, E.N. Perencevich, M. Shardell, S. Leekha, A.D. Harris, Transfer of multidrug-resistant bacteria to healthcare workers' gloves and gowns after patient contact increases with environmental contamination. Crit. Care Med. 40, 1045-1051 (2012)

79. A. Kumar, N. Chordia, Bacterial resistance against antibiotics. in Drug Resist. Bact. Fungi, Malaria, Cancer. G. Arora, A. Sajid, and V. C. (Eds. Kalia, Eds. (Springer International Publishing, 2017)

80. J.A. Bengoechea, C.G. Bamford, SARS -CoV-2, bacterial co-infections, and AMR : the deadly trio in COVID -19? EMBO Mol. Med. 12, e12560 (2020)

81. N. Shi, X. Guo, H. Jing, J. Gong, C. Sun, K. Yang, Antibacterial effect of the conducting polyaniline. J. Mater. Sci. Technol. 22, 289-290 (2006)

82. E. Sharifipour, S. Shams, M. Esmkhani, J. Khodadadi, R. FotouhiArdakani, A. Koohpaei, Z. Doosti, S. Ej Golzari, Evaluation of bacterial co-infections of the respiratory tract in COVID-19 patients admitted to ICU. BMC Infect. Dis. 20, 646 (2020)

83. S. Gomez-Carretero, R. Nybom, A. Richter-Dahlfors, Electroenhanced antimicrobial coating based on conjugated polymers with covalently coupled silver nanoparticles prevents Staphylococcus aureus biofilm formation. Adv. Healthc. Mater. 6, 01700435 (2017)

84. M.R. Gizdavic-Nikolaidis, J.R. Bennett, S. Swift, A.J. Easteal, M. Ambrose, Broad spectrum antimicrobial activity of functionalized polyanilines. Acta Biomater. 7, 4204-4209 (2011)

85. E.-R. Kenawy, S. Kandil, Synthesis, antimicrobial activity and applications of polymers with ammonium and phosphonium groups. in Polym. Mater. with Antimicrob. Act. From Synth. to Appl. (Royal Society of Chemistry, 2013)

86. S.L. Lee, C.J. Chang, Recent developments about conductive polymer based composite photocatalysts. Polymers (Basel). 11, 206 (2019)

87. A. Varesano, C. Vineis, A. Aluigi, F. Rombaldoni, C. Tonetti, G. Mazzuchetti, Antibacterial efficacy of polypyrrole in textile applications. Fibers Polym. 14, 36-42 (2013)

88. E. Nazarzadeh Zare, M. Mansour Lakouraj, M. Mohseni, Biodegradable polypyrrole/dextrin conductive nanocomposite: Synthesis, characterization, antioxidant and antibacterial activity. Synth. Met. 187, 9-16 (2014)

89. M. Cabuk, M. Yavuz, H.I. Unal, Y. Alan, Synthesis, characterization, and enhanced antibacterial activity of chitosan-based biodegradable conducting graft copolymers. Polym. Compos. 36, 497-509 (2015)

90. J. Robertson, M. Gizdavic-Nikolaidis, M.K. Nieuwoudt, S. Swift, The antimicrobial action of polyaniline involves production of oxidative stress while functionalization of polyaniline introduces additional mechanisms. PeerJ. 6, e5135 (2018)

91. C. Dhivya, S.A.A. Vandarkuzhali, N. Radha, Antimicrobial activities of nanostructured polyanilines doped with aromatic nitro compounds. Arab. J. Chem. 12, 3785-3798 (2019)

92. M. Maruthapandi, A. Saravanan, J.H.T. Luong, A. Gedanken, Antimicrobial properties of polyaniline and polypyrrole decorated with zinc-doped copper oxide microparticles. Polymers (Basel). 12, $1286(2020)$

93. A. Kaur, R. Kumar, Enhanced bactericidal efficacy of polymer stabilized silver nanoparticles in conjugation with different classes of antibiotics. RSC Adv. 9, 1095-1105 (2019)

94. B.K. Yoon, J.A. Jackman, E.R. Valle-González, N.J. Cho, Antibacterial free fatty acids and monoglycerides: biological activities, experimental testing, and therapeutic applications. Int. J. Mol. Sci. 19, 1114 (2018)

95. A. Chen, H. Peng, I. Blakey, A.K. Whittaker, Biocidal Polymers: A Mechanistic Overview. Polym. Rev. 57, 276-310 (2017)

96. M.R. Gizdavic-Nikolaidis, A.J. Easteal, S. Stepanovic, Bioactive aniline copolymers. in U.S. Pat. Trademark Off. (2016)

97. K. Raghvendra, L. Sravanthi, Fabrication techniques of micro/ nano fibres based nonwoven composites: a review. Mod. Chem. Appl. 5, 1000206 (2017)

98. Y. Lu, J. Jiang, S. Yoon, K.S. Kim, J.H. Kim, S. Park, S.H. Kim, L. Piao, High-performance stretchable conductive composite fibers from surface-modified silver nanowires and thermoplastic polyurethane by wet spinning. ACS Appl. Mater. Interfaces 10, 2093-2104 (2018)

99. Q. Tian, Z. Xu, Y. Liu, B. Fang, L. Peng, J. Xi, Z. Li, C. Gao, Dry spinning approach to continuous graphene fibers with high toughness. Nanoscale. 9, 12335-12342 (2017)

100. T. Onggar, I. Kruppke, C. Cherif, Techniques and processes for the realization of electrically conducting textile materials from intrinsically conducting polymers and their application potential. Polymers (Basel). 12, 2867 (2020) 
101. B. Kim, V. Koncar, E. Devaux, C. Dufour, P. Viallier, Electrical and morphological properties of PP and PET conductive polymer fibers. Synth. Met. 146, 167-174 (2004)

102. T.H. Lim, S.H. Lee, S.Y. Yeo, Highly conductive polymer/metal/ carbon nanotube composite fiber prepared by the melt-spinning process. Text. Res. J. 87, 593-606 (2017)

103. S. Ojha, Structure-property relationship of electrospun fibers. in Woodhead Publ. Ser. Text. M. B. T.-E. N. Afshari, Ed. (Woodhead Publishing, 2017)

104. P.P. Mehta, V.S. Pawar, Electrospun nanofiber scaffolds: technology and applications. in Woodhead Publ. Ser. Biomater. Inamuddin, A. M. Asiri, and A. Mohammad, Eds. (Woodhead Publishing, 2018)

105. D. Li, Y. Xia, Electrospinning of nanofibers: reinventing the wheel? Adv. Mater. 16, 1151-1170 (2004)

106. S. Thenmozhi, N. Dharmaraj, K. Kadirvelu, H.Y. Kim, Electrospun nanofibers: new generation materials for advanced applications. Mater. Sci. Eng. B Solid-State Mater. Adv. Technol. 217, 36-48 (2017)

107. R. Castagna, M. Tunesi, B. Saglio, C. Della Pina, A. Sironi, D. Albani, C. Bertarelli, E. Falletta, Ultrathin electrospun PANI nanofibers for neuronal tissue engineering. J. Appl. Polym. Sci. 133, 43885 (2016)
108. B. Bessaire, M. Mathieu, V. Salles, T. Yeghoyan, C. Celle, J.P. Simonato, A. Brioude, Synthesis of continuous conductive PEDOT: PSS nanofibers by electrospinning: a conformal coating for optoelectronics. ACS Appl. Mater. Interfaces 9, 950-957 (2017)

109. A. Ehsani, A.A. Heidari, H.M. Shiri, Electrochemical pseudocapacitors based on ternary nanocomposite of conductive polymer/graphene/metal oxide: an introduction and review to it in recent studies. Chem. Rec. 19, 908-926 (2019)

110. W. Zheng, X. Lu, S.C. Wong, Electrical and mechanical properties of expanded graphite-reinforced high-density polyethylene. J. Appl. Polym. Sci. 91, 2781-2788 (2004)

111. K. Kośla, M. Olejnik, K. Olszewska, Preparation and properties of composite materials containing graphene structures and their applicability in personal protective equipment: a review. Rev. Adv. Mater. Sci. 59, 215-242 (2020)

112. J. Du, H.-M. Cheng, The Fabrication, Properties, and Uses of Graphene/Polymer Composites. Macromol. Chem. Phys. 213, 1060-1077 (2012)

113. S. Bhattacharjee, R. Joshi, A.A. Chughtai, C.R. Macintyre, Graphene modified multifunctional personal protective clothing. Adv. Mater. Interfaces 6, 1900622 (2019)

114. SC Tjong, Polymer composites with carbonaceous nanofillers: properties and applications (Wiley, 2012) 